\title{
Inhibition Mechanism of Pitting Corrosion of Nickel in Aqueous Medium by Some Macrocyclic Compounds
}

\author{
Fatma Mohamed Mahgoub ${ }^{1,2}$, Ahmed Mohamed Hefnawy ${ }^{2}$ \\ ${ }^{1}$ Department of Chemistry, Faculty of Science, King Abdaziz University, Jeddah, Saudi Arabia \\ ${ }^{2}$ Department of Materials Science, Institute of Graduate Studies and Research, Alexandria University, Alexandria, Egypt \\ Email: ftm_mahgoub@yahoo.com
}

Received July 26, 2012; revised August 27, 2012; accepted September 29, 2012

\begin{abstract}
Anodic polarization of nickel was studied by potentiostatic technique in neutral media in presence of two macrocyclic ligands. Pit initiation was detected by measuring pitting potential, $E_{p}$ and the charge transfer, $Q$ during the anodic polarization. Initiation of pitting and $\mathrm{Q}$ were found to be dependent on the structure and concentrations of inhibitors. Under steady state conditions, the inhibition efficiency was in the order $1,4,8,11$ tetraazacyclotetradecane $($ cyclam $)>\mathrm{N}$, N'-bis (2-aminoethyl) 1, 3-propandiamine (2,3,2-tet) due to macrocyclic effect. These findings were confirmed by fitting the data to different adsorption isotherms. Adsorption on nickel surface was obeyed kinetic-thermodynamic model for the two inhibitors. Influence of $\left[\mathrm{Cl}^{-}\right]$on corrosion behavior of nickel in sulphate solution containing inhibitors was investigated. A mechanism involving three competitive equilibria of dissolution of nickel in presence and absence of the inhibitors was proposed. Empirical and theoretical kinetic equations were compared and discussed. There is a good agreement between the calculated and observed rate constants.
\end{abstract}

Keywords: Organic Inhibitors; Polarization; Pitting

\section{Introduction}

The importance of nickel as basic material for corrosion resistant alloys and its catalytic properties with respect to many organic reactions is well recognized [1]. Although nickel is known as corrosion resistant metal in many aggressive media, it corrodes at a significant rate in the presence of mineral acids or in neutral medium.

Increased resistance of passive metals to localized corrosion in aqueous-chloride containing solutions often can be obtained by addition of certain compounds at concentrations much lower than that of chloride ion [2]. Jha et al. studied the effect of dicyandiamide, biguanide, and guanylurea on corrosion of nickel in neutral medium [3-5]. They found that the presence of the inhibitors promote considerable inhibition at higher concentration as well as with increasing the temperature. The inhibition characteristics and quantum chemical data show that corrosion current depends mainly upon the energy of the Highest Occupied Molecular Orbital (HOMO) while Lowest Unoccupied Molecular Orbital (LUMO) gives an idea about electron affinity of the molecule. Polarization characteristics of $\mathrm{Ni}$ were measured in $0.5 \mathrm{M} \mathrm{K}_{2} \mathrm{SO}_{4}$ in the presence and absence of dimethylacrylamide (DMA) [6]. The changes in the composition of the surface of the electrode were examined by XPS which indicated a change in the chemical nature of the surface; the hydroxide layer is covered with an additive film (NiOOH/DMA). The high efficiency is due to the presence of two double bonds and a tertiary nitrogen atom. Effect of a number of benzimidazole derivatives in inhibiting the anodic dissolution of nickel in aqueous solutions of lithium perchlorate were made [7]. The effectiveness of inhibition depended on the electrode potential and the nature of the substituent in the organic molecule. The effect of the concentration and chemical nature of anions-activators, the $\mathrm{pH}$ and solution temperature on the inhibition process of pitting of nickel has been studied [8]. The relationship between the potential of pitting $\left(E_{P}\right)$ and chemical nature of the anion was described quantitatively using the hydrophobic and electronic characteristics of anion. The existence of the limited value of $\left(E_{p}\right)$, which does not depend on concentration but only on its chemical nature, was shown.

The mechanisms of inhibition of localized corrosion are quite difficult to establish in view of the complexity of the localized corrosion process coupled with all of the possible interactions of the inhibitor with surface or inter phase chemistry [9-12]. Literature survey showed little work appears to have been made on the use of chelating ligands as corrosion inhibitors for nickel, particularly in neutral medium. Multidentate ligands [13] making available two or more donor atoms for binding and hence are thought to have superior inhibition efficiency to monoden- 
tate ligands. The cyclic nature of these ligands is thought to enhance ligation [14-17]. Just as a chelating n-dentate ligand gives a more stable complex than unidentate ligand of a similar type, a phenomenon known as the chelate effect. So an n-dentate macrocyclic ligand gives even more stable complexes than the most similar n-dentate open chain ligand. This so called macrocyclic effect results from a favorable entropy change assisted, usually by favorable enthalpy change as well $[18,19]$.

The purpose of the present study is to investigate the corrosion inhibition characteristics of the qundridenate macrocyclic ligand 1, 4, 8, 11, tetraaza-cyclotetradecane (cyclam) and its open chain analogous N, N'-bis (2amino ethyl) 1, 3-propandiamine (2,3,2-tet) on nickel dissolution in neutral media. In addition, to study the kinetics and mechanism of pitting corrosion of nickel in presence of inhibitors.

\section{Experimental}

Nickel dissolution rate was determined using DC cyclic anodic polarization. Electrochemical polarization measurements were achieved by connecting the cell to Wenking potentiostat. The working electrode was nickel wire (BDH, $99.99 \%$ ) with $1.25 \mathrm{~mm}$ in diameter. Before the measurements, the specimens being used were polished with a series of emery papers with different grades (320 - 600 - 1200 grit), starting with a coarse one and proceeding in steps to fine grades. The rods were washed thoroughly with distilled water and dried with ethanol. All the experiments were thermostated at room temperature. The sweeping rate used in this study was $1 \mathrm{mV} / \mathrm{sec}$. Electrode potentials were measured vs. reference Saturated Calomel Electrode (SCE).

The macrocyclic inhibitors studied were N,N'-bis (2aminoethyl)-1,3-propane diamine (2,3,2-tet), and 1,4,8, 11-tetra-azacyclo-tetradecane, (cyclam) were purchased from $\mathrm{BDH}$ and Aldrich chemical companies respectively and were used without further purification.

The inhibition efficiency of the compounds used in retarding the corrosion of nickel could be measured by evaluating the percentage inhibition, $\% P$, from the following relationship:

$$
\% P=100 \times\left(1-\frac{q_{i}}{q}\right)
$$

where $q$ and $q_{i}$ are the charge transfer per unit area in the absence and the presence of inhibitor respectively.

$$
q=\frac{Q}{A \cdot F} \text { electron - equivalent } / \mathrm{cm}^{2}
$$

where $A$ is the electrode area, $F$ is Faraday constant and $Q$ is the number of coulombs of electric charge consumed in the electrode process. $Q$ is evaluated by integration of $\mathrm{i}-\mathrm{V} f(t)$ diagrams of the cyclic polarization according to the following equation:

$$
Q=\int i . d t \text { coulombs }
$$

\section{Results and Discussion}

\section{Inhibition effects of macrocyclic ligands on pitting corrosion of nickel}

The potentiodynamic scan began at $-0.1 \mathrm{~V}$ vs SCE and extended to $1.0 \mathrm{~V}$ (vertex point), followed by a reverse scan back to a final potential of $-0.1 \mathrm{~V}$. Figure 1 represents the cyclic polarization $\mathrm{i}-\mathrm{V} f(\mathrm{t})$ curves of nickel in deareated $0.1 \mathrm{M} \mathrm{KCl}$ solution with and without different concentrations of the 2,3,2-tet. The effect of cyclam and 2,3,2-tet on the electrochemical parameters is manifested in Table 1. The degree of hysteresis indicates the tendency toward localized corrosion or pit formation. From these curves, it can be observed that the presence of 2,3,2-tet in the medium leads to improve the inhibition of pitting corrosion by shifting the critical pitting potential of initiation $\left(E_{p}\right)$ towards more positive values. Besides, the hysteresis area became less and accompanied with a reduction of the integral charge transfer of the anodic dissolution process $(q)$. Diminished area of hysteresis means that the protected nickel suffers fewer tendencies towards pitting corrosion and its corrosion resistance increases. Findings reveal also that Ep shifts to more positive values and enhancing the concentration of $c y$ clam and 2,3,2-tet in the medium leads the quantity of charge required for passivation gradually decreased suggesting that the adsorption of the inhibitors molecules on nickel surface inhibits the dissolution of nickel.

Figure 2 shows the effect of $2 \times 10^{-3} \mathrm{M}$ of 2,3,2-tet and cyclam on anodic polarization cycle in chloride solution. Figure 3 shows the variation of the percentage inhibition $(\% P)$ as a function of the logarithm of molar concentration of the two inhibitors. The role of the inhibitor on passivating metals is to repair the breakdowns in the oxide film which are assumed to occur mainly at

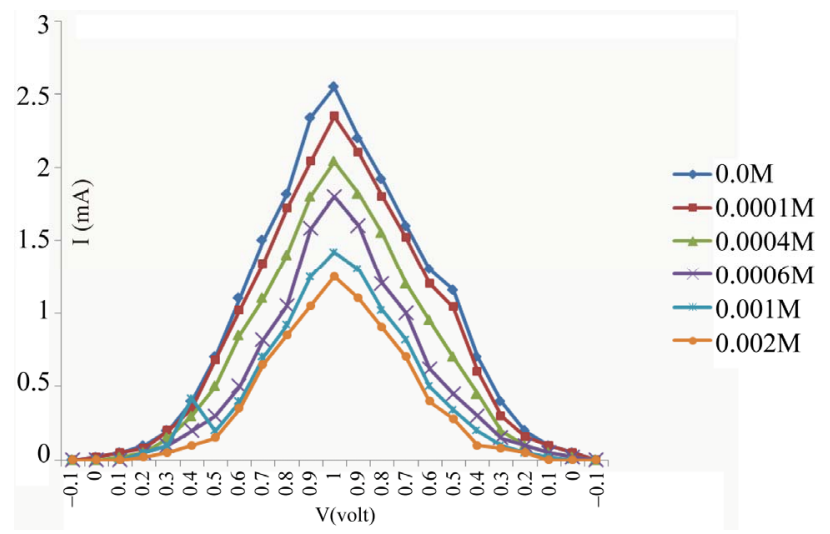

Figure 1. Effect of increasing the concentration of 2,3,2-tet on polarization cycle in $0.1 \mathrm{M} \mathrm{KCl}$. 
Table 1. Electrochemical parameters obtained from D.C. polarization measurements of nickel in $0.1 \mathrm{M} \mathrm{KCl}$.

\begin{tabular}{|c|c|c|c|c|c|c|}
\hline Inhibitor & \multicolumn{3}{|c|}{ Cyclam } & \multicolumn{3}{|c|}{$2,3,2$-tet } \\
\hline $\begin{array}{l}\text { Conc. } \\
\text { M }\end{array}$ & $\begin{array}{l}q \times 10^{-5} \text { elec- } \\
\text { tron equiv. } / \mathrm{cm}^{2}\end{array}$ & $E_{p} V$ & $\% P$ & $\begin{array}{c}q \times 10^{-5} \text { electron } \\
\text { equiv. } / \mathrm{cm}^{2}\end{array}$ & $\mathrm{E}_{\mathrm{p}} \mathrm{V}$ & $\% P$ \\
\hline 0.0 & 1.72 & 0.00 & - & 1.72 & 0.00 & - \\
\hline $1 \times 10^{-4} \mathrm{M}$ & 1.48 & 0.09 & 13.7 & 1.59 & 0.05 & 7.47 \\
\hline $4 \times 10^{-4} \mathrm{M}$ & 1.12 & 0.14 & 34.8 & 1.31 & 0.07 & 23.65 \\
\hline $6 \times 10^{-4} \mathrm{M}$ & 0.82 & 0.20 & 52.2 & 1.01 & 0.10 & 41.20 \\
\hline $1 \times 10^{-3} \mathrm{M}$ & 0.65 & 0.31 & 62.5 & 0.81 & 0.18 & 52.95 \\
\hline $2 \times 10^{-3} \mathrm{M}$ & 0.55 & 0.40 & 68.2 & 0.68 & 0.21 & 60.30 \\
\hline
\end{tabular}

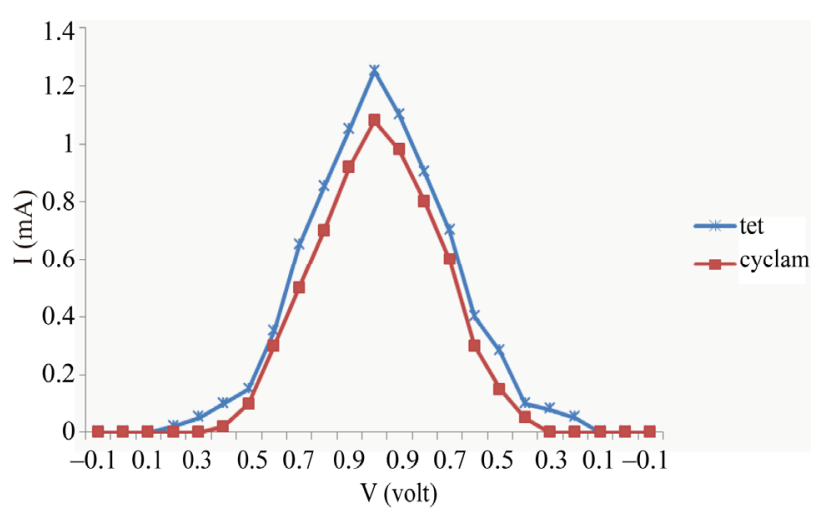

Figure 2. Effect of $0.002 \mathrm{M}$ inhibitors on anodic polarization cycle in $0.1 \mathrm{M} \mathrm{KCl}$.

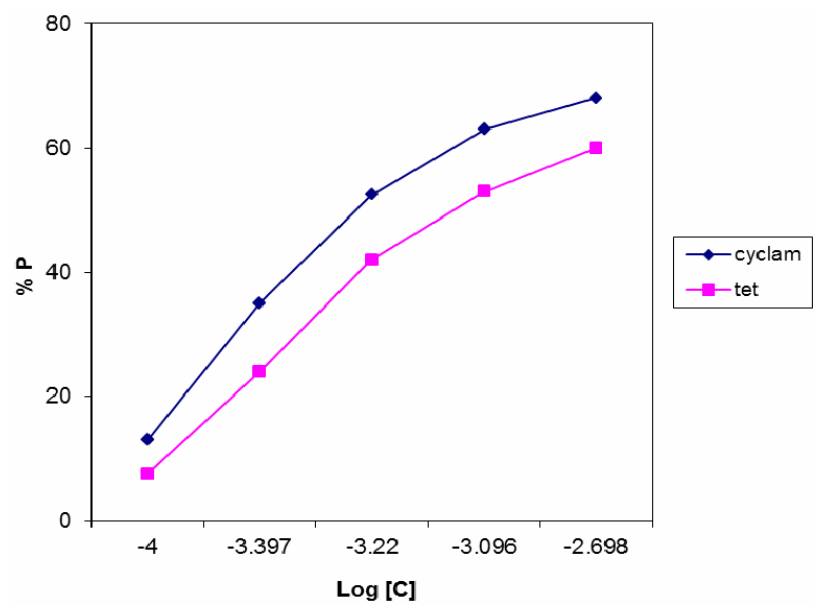

Figure 3. Relationship between percentage inhibition and log concentration of inhibitors.

the inclusion sites or grain boundaries [20] or to block the oxide surface. Figures 2 and $\mathbf{3}$ show that the inhibition of cyclam is more efficient than 2,3,2-tet. These could be attributed to the macrocyclic effect where cyclam is a cyclic compound while 2,3,2-tet is an open chain one. The cyclic nature of these ligands is thought to enhance ligation. Besides, macrocyclic ligands are known to form stable complexes with metals in their zero oxidation state [19] or in this study as nickel hydroxide/inhibitor complex.
Kinetic-thermodynamic model and adsorption isotherms analyses

The data obtained from DC measurements have been fitted to the kinetic thermodynamic model in terms of active site occupancy parameter, $y$, and binding constant of the inhibitor with the metallic surface, $K$. The obtained results are compared with fits executed from the application of Langmuir, Frumkin and Flory-Huggins adsorption isotherms.

The curve fitting for 2,3,2-tet and cyclam data to the Langmuir isotherm (Equation (4)), Frumkin isotherm (Equation (5)) and Flory-Huggins isotherm (Equation (6)) are given in Figures 4(a)-(c), respectively. The results indicate that the data does not fit any of the above isotherms.

$$
\begin{gathered}
\frac{\theta}{1-\theta}=K C \\
{\left[\frac{\theta}{1-\theta}\right] \exp [-2 a \theta]=K C}
\end{gathered}
$$

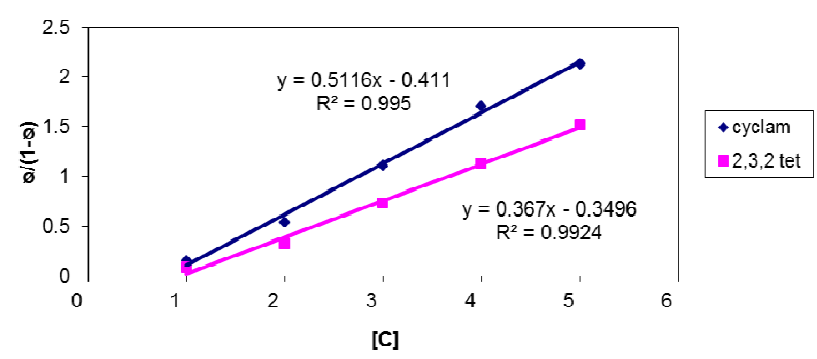

(a)

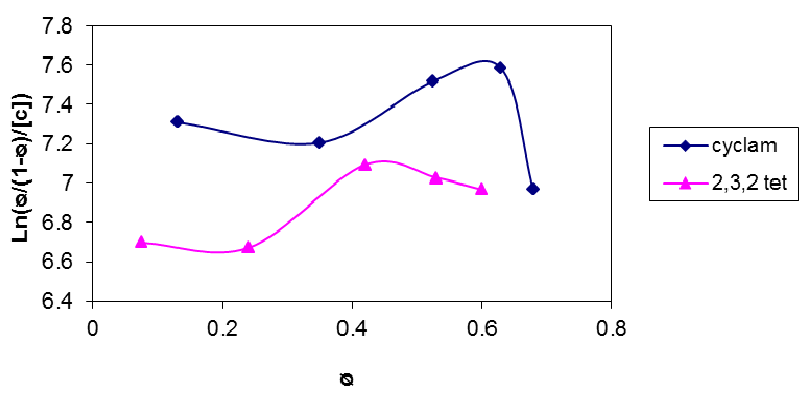

(b)

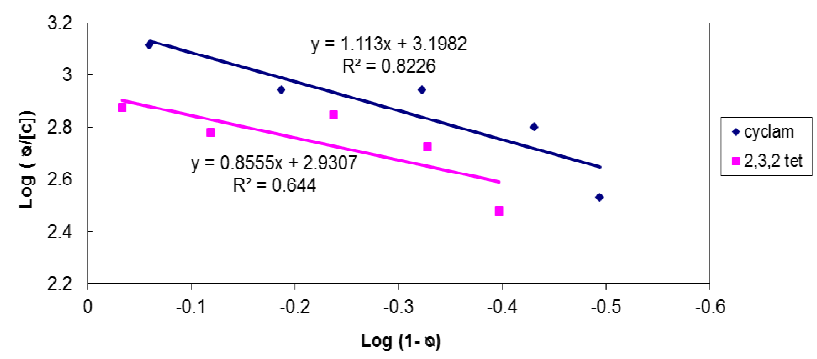

(c)

Figure 4. (a) Test of Langmuir adsorption isotherm; (b) Test of Frumkin adsorption isotherm; (c) Test of Flory-Huggins adsorption isotherm. 


$$
\frac{\theta}{x(1-\theta)^{x}}=K C
$$

where $\theta$ is surface coverage, $C$ is the inhibitor concentration, $\mathrm{a}$ is a molecular interaction parameter depending on the molecular interactions in the adsorption layer and on the degree of heterogeneity of the surface, and $x$ is the size ratio and is simply the number of water molecules replaced by one molecule of organic adsorbate.

The curve fitting of the obtained data using cyclam and 2,3,2-tet to kinetic-thermodynamic model (Equation (7)) is given in Figure 5.

$$
\begin{gathered}
\log \frac{\theta}{1-\theta}=\log K^{\prime}+y \log C \\
K=K^{\prime(1 / y)}
\end{gathered}
$$

As can be seen, good straight lines fit are given for the compounds used. The slope of the lines is representing $y$, the number of inhibitor molecules occupying a single active site. The intercept is $\log K^{\prime}$. ( $\left.1 / y\right)$ gives the number of active sites occupied by a single inhibitor molecule. Table 2 gives the adsorption parameters obtained from Kinetic-thermodynamic model using cyclam and 2,3,2-tet. The table displays that the value of $K$ increases from 931 to 1442 for 2,3,2-tet and cyclam respectively.

This clearly indicates that the strength of electrical interactions by adsorbing molecules and surface of the metal increases in the same order noticed previously and hence the percentage inhibition. The results show also that $(1 / y)$ values are approximately equal to the unity indicating that the adsorption process takes place by the occupation of one active site per a single inhibitor molecule. $\Delta \mathrm{G}_{\text {ads }}^{\mathrm{o}}$ was -ve values mean spontaneous adsorption of inhibitor on the metal surface.

Kinetics study of pitting corrosion of nickel in $\mathrm{Na}_{2} \mathrm{SO}_{4}$ media containing $\mathrm{CI}$ ions

Figure 6 shows the anodic potentiodynamic polarization curves of nickel in $1.0 \mathrm{M} \mathrm{Na}_{2} \mathrm{SO}_{4}$ containing different concentrations of $\mathrm{KCl}$. Inspection of this Figure shows that pitting potential was shift to the less positive potential direction with increasing $\left[\mathrm{Cl}^{-}\right]$. MacDougall [21] discussed this behavior on the basis that $\mathrm{E}_{\mathrm{p}}$ becomes progressively easier to initiate pitting at higher $\left[\mathrm{Cl}^{-}\right]$. The more $\mathrm{Cl}^{-}$ion in solution leads to the larger active areathat can be generated and the lower the anodic overvoltage

Table 2. Binding constant, number of active sites and change of free energy obtained from kinetic-thermodynamic model for 2,3,2-tet and cyclam.

\begin{tabular}{cccc}
\hline Inhibitor & $\mathrm{K}$ & $1 / \mathrm{y}$ & $\Delta \mathrm{G}_{\text {ads }}^{\mathrm{o}}(\mathrm{kJ} / \mathrm{mol})$ \\
\hline 2,3,2-tet & 931 & 0.97 & -26.4 \\
Cyclam & 1442 & 1.00 & -27.5 \\
\hline
\end{tabular}

for a particular charging rate. The Figure also indicates that after a period of continuous dissolution prior to about 1.0 volt, all anodic polarization curves are characterized by a limiting current. The limiting current value increases with the increase of the concentration of $\mathrm{Cl}^{-}$ ions due to the ability of $\mathrm{Cl}^{-}$to interfere with oxide formation and thereby decrease the repair efficiency. This causes further metal dissolution and even more $\mathrm{Cl}^{-}$migration into the breakdown area [21]. The limiting current values could be considered as rate constant, $k_{0}$, in the absence of $\left[\mathrm{Cl}^{-}\right]$and as $k_{\text {obs }}$ in the presence of different concentrations of $\mathrm{Cl}^{-}$ion.

Figure 7 represents a plot of $\left(k_{o b s}-k_{o}\right)$ vs $\left[\mathrm{Cl}^{-}\right]$concentrations, the Figure confirms the following rate expression $[17,23]$

$$
\left(k_{o b s}-k_{o}\right)=\frac{a\left[\mathrm{Cl}^{-}\right]^{2}}{b+c\left[\mathrm{Cl}^{-}\right]}
$$

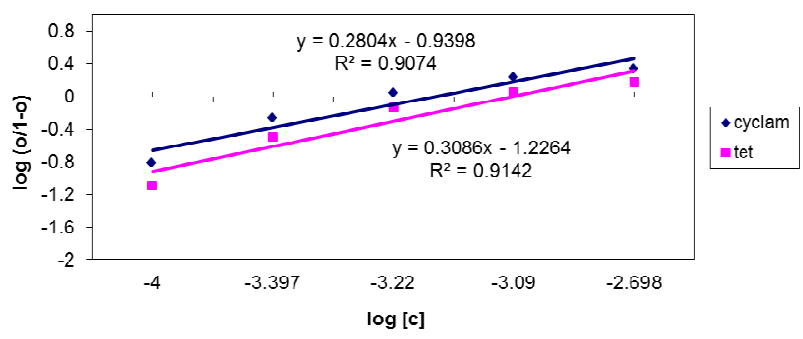

Figure 5. Test of kinetic-thermodynamic model.

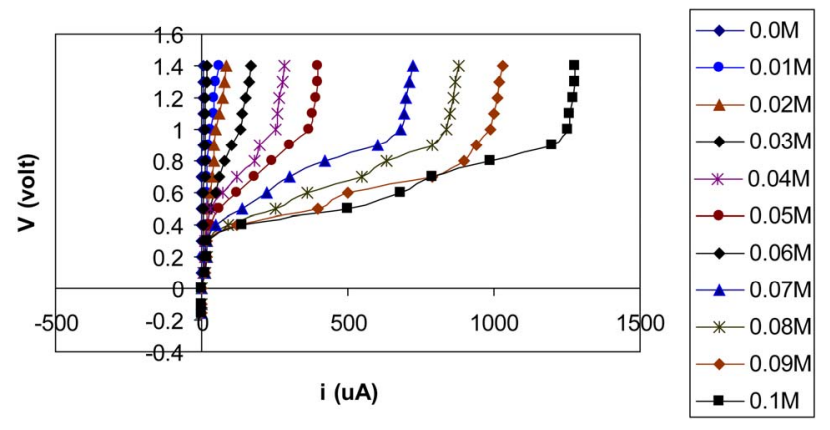

Figure 6. Anodic potentiodynamic polarization curves of nickel in $1.0 \mathrm{M} \mathrm{Na}_{2} \mathrm{SO}_{4}$ containing different concentrations of $\mathrm{KCl}$.

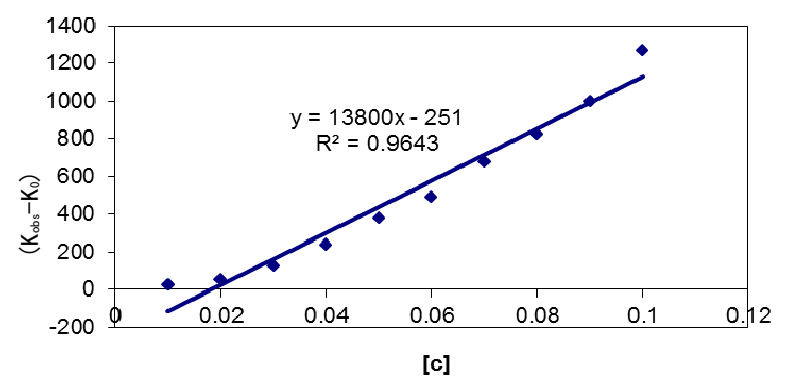

Figure 7. Plot of $\left(\mathrm{k}_{o b s}-\mathrm{k}_{o}\right)$ vs $\left[\mathrm{Cl}^{-}\right]$for corrosion of nickel in 1.0 $\mathrm{M} \mathrm{Na}_{2} \mathrm{SO}_{4}$. 
Equation (9) refers to a number of possible mechanisms. These mechanisms could involve competitive anion adsorption, anion migration through the passive film, competition between metal dissolution and film repair or localized attack at preexisting flaws in the passive film. In other words, $\mathrm{Cl}^{-}$ion is expected to enhance nickel dissolution probably through preferential adsorption of $\mathrm{Cl}^{-}$ on the Ni surface or it may delay passive film formation, probably via an interaction with soluble intermediate compound. $\mathrm{Cl}^{-}$ion also could attack the precipitated oxide leading to damage its protective nature. In the $\mathrm{pH}$ range of the electrolyte considered in this study and according to the theoretical equilibrium diagram the main stable corrosion product in the passive film is expected to be $\mathrm{Ni}_{2} \mathrm{O}_{3} \cdot \mathrm{H}_{2} \mathrm{O}$. Employing differential reflectometry in conjugation with ESCA, it has been proved that $\mathrm{Ni}(\mathrm{OH})_{2}$ film is mainly observed on pure $\mathrm{Ni}$ in $0.15 \mathrm{~N} \cdot \mathrm{Na}_{2} \mathrm{SO}_{4}$ [22].

The proposed a mechanism in which $\mathrm{Cl}^{-}$ions are adsorbed on the metal surface in competition with $\left(\mathrm{H}_{2} \mathrm{O}\right)_{\text {ads }}$, followed by a rate determined dissolution step (R.D.S) that is catalyzed by $\mathrm{Cl}^{-}$ions.

$$
\begin{aligned}
& \mathrm{Ni}+\mathrm{H}_{2} \mathrm{O} \stackrel{K_{1}}{\Leftrightarrow} \mathrm{Ni}\left(\mathrm{H}_{2} \mathrm{O}\right)_{\text {ads }} \\
& \mathrm{Ni}+\mathrm{Cl}^{-} \stackrel{K_{2}}{\Leftrightarrow} \mathrm{Ni}\left(\mathrm{Cl}^{-}\right) \text {ads } \\
& \mathrm{Ni}\left(\mathrm{Cl}^{-}\right)_{\text {ads }} \Leftrightarrow \mathrm{NiCl}+\mathrm{e}^{-} \\
& \mathrm{NiCl}+\mathrm{Cl}^{-} \underset{\text { R.D.S }}{\stackrel{k}{\Leftrightarrow}} \mathrm{NiCl}_{2} \text { (aq.) }+\mathrm{e}^{-}
\end{aligned}
$$

or

$$
\mathrm{Ni}\left(\mathrm{Cl}^{-}\right) \text {ads }+\mathrm{Cl}^{-} \underset{\text { R.D.S }}{\stackrel{k}{\Leftrightarrow}} \mathrm{NiCl}_{2}+2 \mathrm{e}^{-}
$$

This mechanism is similar to the mechanism of dissolution of $\mathrm{Al}$ in $\mathrm{HCl}$ [23] and leads to an observed rate constant dependence on $\mathrm{Cl}^{-}$of the form:

$$
k_{o b s}=\frac{k K_{2}\left[\mathrm{Cl}^{-}\right]^{2}}{1+K_{1}\left(\mathrm{H}_{2} \mathrm{O}\right)+K_{2}\left[\mathrm{Cl}^{-}\right]}
$$

Under the conditions $K_{1}\left(\mathrm{H}_{2} \mathrm{O}\right) ; K_{2}\left[\mathrm{Cl}^{-}\right] \gg 1$, Equation (10) reduces to:

$$
k_{\text {obs }}=\frac{k K_{2}\left[\mathrm{Cl}^{-}\right]^{2}}{1+K_{1}\left(\mathrm{H}_{2} \mathrm{O}\right)+K_{2}\left[\mathrm{Cl}^{-}\right]}
$$

This condition is equivalent to saying that the surface of the metal is totally covered by either adsorbed $\mathrm{H}_{2} \mathrm{O}$ or $\mathrm{Cl}^{-}$. The inverse form of Equation (11) gives:

$$
\frac{\left[\mathrm{Cl}^{-}\right]}{k_{\text {obs }}}=\frac{1}{k}+\frac{K_{1}\left(\mathrm{H}_{2} \mathrm{O}\right)}{k K_{2}\left[\mathrm{Cl}^{-}\right]}
$$

A plot of the left-hand side of Equation (12) versus
$1 /\left[\mathrm{Cl}^{-}\right]$gave a good straight line (Figure 8). Employing the liner least-square fit of the data, the equilibrium constant, $k$, becomes 0.0519 .

Kinetics of the inhibition of the pitting corrosion of nickel

Anodic potentiodynamic polarization curves of nickel in $1.0 \mathrm{M} \mathrm{Na}_{2} \mathrm{SO}_{4}+0.05 \mathrm{M} \mathrm{KCl}$ solutions containing different concentrations of 2,3,2-tet and cyclam are represented in Figures 9 and $\mathbf{1 0}$ respectively. Inspections of these Figures show that all potential-current curves are characterized by limiting current phenomena. It is observed that the limiting current decrease with the increase of the concentrations of the two inhibitors in the medium and cyclam offer lowering limiting current than 2,3,2-tet. These results confirm the previous data obtained from the percentage inhibition versus the logarithm of the concentration of the inhibitors in Figure 3.

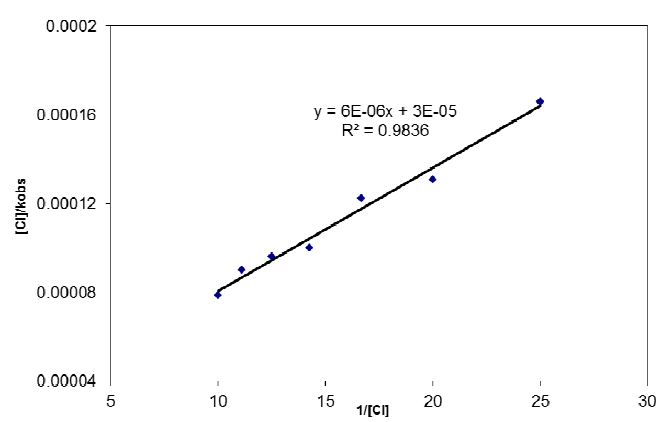

Figure 8. Plot of $\left[\mathrm{Cl}^{-}\right] / \mathrm{k}_{\text {obs }}$ vs $1 /\left[\mathrm{Cl}^{-}\right]$for the $\mathrm{Cl}^{-}$ion catalysis of nickel in $1.0 \mathrm{M} \mathrm{Na}_{2} \mathrm{SO}_{4}$.

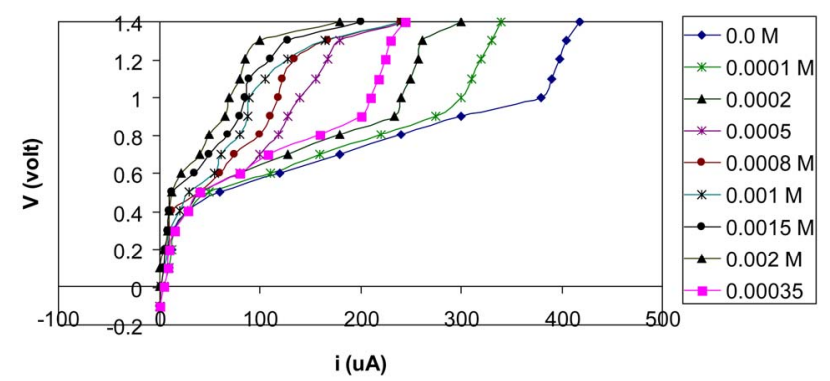

Figure 9. Anodic potentiodynamic polarization curves of nickel in $1.0 \mathrm{M} \mathrm{Na}_{2} \mathrm{SO}_{4}+0.05 \mathrm{M} \mathrm{KCl}$ containing different concenrtrations of 2,3,2-tet.

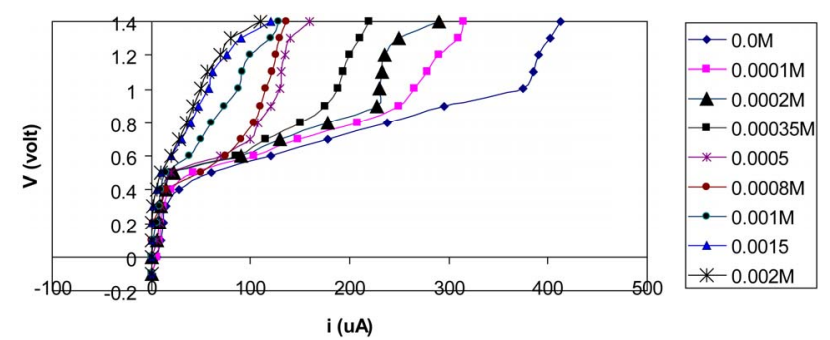

Figure 10. Anodic potentiodynamic polarization curves of nickel in $1.0 \mathrm{M} \mathrm{Na}_{2} \mathrm{SO}_{4}+0.05 \mathrm{M} \mathrm{KCl}$ containing different concenrtrations of cyclam. 


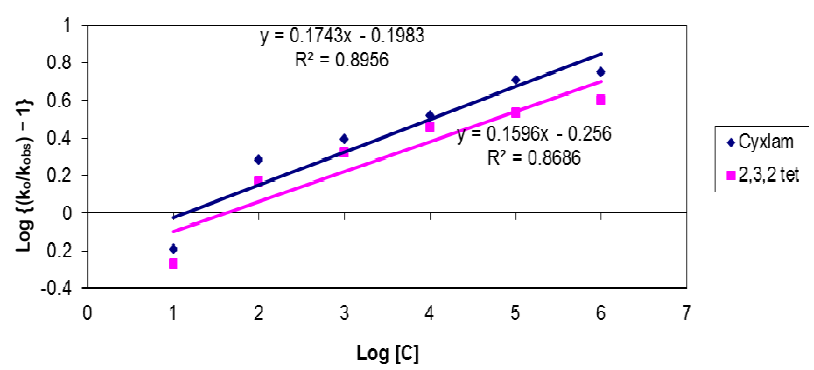

Figure 11. Plot of $\log \left[\left(k_{o} / k_{o b s}\right)-1\right]$ vs $\log [I]$ for corrosion of nickel in the presence of Cyclam and 2,3,2-tet.

The limiting dissolution current can be considered as $k_{o}, k_{o b s}$ in the absence and in the presence of inhibitors. The contribution of the inhibitor molecule, I, in the mechanism of dissolution of nickel in chloride media can be proposed as in the case of dissolution of aluminum in inhibited $\mathrm{HCl}$ solution [23], and can be given as:

$$
\begin{aligned}
& \mathrm{Ni}+\mathrm{H}_{2} \mathrm{O} \Leftrightarrow \mathrm{K} \Leftrightarrow \mathrm{Ni}\left(\mathrm{H}_{2} \mathrm{O}\right) \text { ads } \\
& \mathrm{Ni}+\mathrm{Cl}^{-} \stackrel{K_{2}}{\Leftrightarrow} \mathrm{Ni}\left(\mathrm{Cl}^{-}\right) \text {ads } \\
& \mathrm{Ni}+y \mathrm{I} \Leftrightarrow \mathrm{NiI}_{y \cdot \text { ads }} \\
& \mathrm{Ni}\left(\mathrm{Cl}_{\text {ads }}^{-}\right)+\mathrm{Cl}^{-} \underset{\text { R.D.S }}{\Leftrightarrow} \mathrm{NiCl}_{2}+2 \mathrm{e}^{-}
\end{aligned}
$$

This mechanism leads to the following rate equation:

$$
\log \left(\frac{k_{o}}{k_{o b s}}-1\right)=\log \frac{K_{3}}{K_{1}\left[\mathrm{H}_{2} \mathrm{O}\right]+K_{2}\left[\mathrm{Cl}^{-}\right]}+y \log [I](13)
$$

Figure 11 represents a plot of $\log \left(k_{o} / k_{\text {obs }}-1\right)$ vs. $\log$ [I] for cyclam and 2,3,2-tet. The plot gave a straight line with slope of $y$ and an intercept of $\log \left(K_{3} / K_{2}\left[\mathrm{Cl}^{-}\right]\right)$. The calculated values of $1 / y$ (active site occupancy parameter or number of surface adsorbed water molecules replaced by an inhibitor molecule) obtained from a leastsquare fit are 1.05 and 1.18 for cyclam and 2,3,2-tet respectively which could be considered almost the same as in $0.1 \mathrm{M} \mathrm{KCl}$ solution. Of particular importance, however, is the ratio of the equilibrium constants for cyclam to that of 2,3,2-tet $\left[K_{3}(\right.$ cyclam $) / K_{3}(2,3,2$ tet $\left.)\right]$ which could be considered as a measure of the inhibition effi- ciency of the two ligands. The ratio is 2.3 indicating that cyclam is more efficient than 2,3,2-tet due to the macro- cyclic effect.

\section{Conclusion}

The results appear to demonstrate that adsorption-type organic inhibitors might be of interest in reducing the pitting corrosion of nickel. The corrosion inhibition of the qundridentate macrocyclic ligand (cyclam) is more efficient than its open chain analogous (2,3,2-tet) on nickel dissolution in neutral media.

\section{REFERENCES}

[1] E. Khamis, F. Bellucci, R. M. Latanision and E. S. H. ElAshry, "Acid Corrosion Inhibition of Nickel by 2-(Triphenosphoranylidene) Succinic Anhydride," Corrosion, Vol. 47, No. 9, 1991, pp. 677-686. doi:10.5006/1.3585307

[2] J. Horvath, T. M. Salem, B. A. Abd-EL-Nabey, N. E. Khalil, L. Hackl and A. Rauscher, "Inhibition of the Pitting Corrosion of Stainless Steel in Presence of Cholride and Hydrogen Sulphide," The 41th European Symposium on Corrosion Inhibitors, Ferrara, 15-19 September 1975, p. 743.

[3] L. Jha, G. R. Parida, G. Kaur, and G. Singh, "Corrosion Inhibition of Nickel by Dicyandiamide in Neutral Medium," Journal of the Electrochemical Society of India, Vol. 39, No. 2, 1990, pp. 67-70.

[4] G. Singh, L. Jha, G. R. Parida and G. Kaur, "Study of Corrosion Inhibition Characteristics of Biguanide for Nickel in Neutral Medium," Bulletin of Electrochemistry, Vol. 6, No. 9, 1990, pp. 754-756.

[5] G. Singh, L. Jha, G. Kaur and G. R. Parida, "Corrosion Inhibition of Nickel by Guanylurea in Neutral Medium," Transactions of the Society for Advancement of Electrochemical Science and Technology, Vol. 25, No. 1-2, 1990, pp. 43-49.

[6] L. J. Jha, Indian Journal of Science and Technology, Vol. 28, 1990, p. 636.

[7] V. P. Grigoriev, G. N. Ekilik and E. N. Balakshina, The 6th European Symposium on Corrosion Inhibitors, Ferrara, 16-20 September 1985, p. 335.

[8] Y. I Kuznetsov and O. A. Luk'yanchikov, Zashchita Metallov, Vol. 24, 1988, p. 241.

[9] B. Bavarian, A. Moccari and D. D. Macdonald, "Inhibition of Stress Corrosion Cracking of Type 403 Stainless Steel in Sodium Sulfate Solutions," Corrosion, Vol. 38, No. 22, 1982, pp. 104-116.

[10] D. W. Deberry, G. R. Peyton and W. S. Clark, "Evaluation of Corrosion Inhibitors in $\mathrm{SO}_{2}$ Scrubber Solutions," Corrosion, Vol. 40, No. 5, 1984, pp. 250-256. doi:10.5006/1.3581950

[11] A. Viehbeck and D. W. Deberry, "Inhibition of Localized Corrosion as Determined by a Galvanodynamic Method," Journal of the Electrochemical Society, Vol. 131, No. 8, 1984, pp. 1844-1846. doi:10.1149/1.2115973

[12] D. W. Deberry and A. Viehbeck, "Inhibition of Pitting of Type 304L Stainless Steel by N-Lauroylsarcosine," Journal of The Electrochemical Society, Vol. 133, No. 1, 1986, pp. 30-37. doi:10.1149/1.2108536

[13] D. W. Deberry and A. Viehbeck, "Inhibition of Pitting Corrosion of AISI 304L Stainless Steel by Surface Active Compounds," Corrosion, Vol. 44, No. 5, 1988, pp. 299-305. doi: $10.5006 / 1.3583941$

[14] B. A. Abd-El-Nabey, M. A. Khalifa , E. Khamis, A. F. Hefny and A. R. Michael, "Macrocyclic Effects in Corrosion Inhibition," Corrosion Prevention and Control, Vol. 35, 1988, p. 154.

[15] A. A. El-Awady, B. A. Abd-El-Nabey, S. G. Aziz, M. Khalifa, H. A. Al-Ghamidy and A. R. Michael, "Kinetics and 
Thermodynamics of the inhibition of the Acid Corrosion of Steel by Some Macrocyclic Ligands," International Journal of Chemical Kinetics, Vol. 35, 1990, p. 169.

[16] B. A. Abd-El-Nabey and A. A. Samarkandy, "Inhibition of the Pitting Corrosion of Nickel by Macrocyclic Ligands," International Journal of Chemistry, Vol. 3, No. 2, 1991, p. 111.

[17] A. El-Awady, B. A. Abd-El Naby and S. G. Aziz, "Kinetic-Thermodynamic and Adsorption Isotherms Analyses for the Inhibition of the Acid Corrosion of Steel by Cyclic and Open-Chain Amines," Journal of The Electrochemical Society, Vol. 139, No. 8, 1992, pp. 2149-2154. doi:10.1149/1.2221193

[18] F. A. Cotton and G. Wilkinson, "Advanced Inorganic Chemistry," 4th Edition, Interscience Publication, New York, 1980.

[19] F. P. Hipz and D. W. Marerum, "Effect of Ligand Solvation on the Stability of Metal Complexes in Solution. Explanation of the Macrocyclic Effect," Journal of the American Chemical Society, Vol. 96, No. 15, 1974, pp. 4993-
4994. doi:10.1021/ja00822a050

[20] G. Pallos and G. Wallwork, "Inhibition of Pitting Corrosion of Mild Steel in Neutral Solutions," Corrosion, Vol. 38, No. 6, 1982, pp. 305-313. doi:10.5006/1.3621690

[21] B. MacDougall and M. J. Graham, "Pitting of Nickel during Anodic Galvanostatic Charging in $\mathrm{Na}_{2} \mathrm{SO}_{4}$ Solutions," Electrochemical Acta, Vol. 27, No. 8, 1982, pp. 1093-1096. doi:10.1016/0013-4686(82)80115-1

[22] R. E. Hummel, R. J. Smith and E. D. Verink Jr, "The Passivation of Nickel in Aqueous Solutions I-The Identification of Insoluble Corrosion Products on Nickel Electrodes Using Optical and ESCA Techniques," Corrosion Science, Vol. 27, No. 8, 1987, pp. 803-813. doi:10.1016/0010-938X(87)90038-2

[23] A. A. El-Awady, B. A. Abd-El-Nabey and S. C Aziz, "Thermodynamic and Kinetic Factors in Ion Pitting and Nitrogen Donor Ligand Inhibition of Aluminium Metal Corrosion in Aggressive Acid Media," Journal of the Chemical Society, Vol. 89, 1993, pp. 795-802. 